\title{
Analytical and Numerical Analysis of the Strength Performance of a Novel Ship Construction Profile
}

\author{
(1) Ahmet Taşdemir ${ }^{1}$, (1) Serkan Nohut ${ }^{2}$, ๑ Mehmet Akman³ \\ ${ }^{1}$ Piri Reis University, Maritime Faculty, Department of Marine Engineering, İstanbul, Turkey \\ ${ }^{2}$ Piri Reis University, Faculty of Engineering, Department of Mechanical Engineering, İstanbul, Turkey \\ ${ }^{3}$ Muğla Sitkı Koçman University, Department of Motor Vehicles and Transportation Technologies, Muğla, Turkey
}

\begin{abstract}
Construction profiles in different shapes such as bulb flats, tees, channels, and angles are widely used in the shipbuilding industry. During the ship construction process, these conventional profiles are joined to the plates as stiffeners and are dimensioned according to class rules. This article investigates the structural performance of a novel construction profile, the so-called TP profile, that can be used in the hull construction of ships and of which form is inspired by the human bone geometry. The cross-sectional area and the weight of the TP profile are designed to be equal to those of the conventional HP profile and commercial T profile. Strength performances of these profiles are compared via analytical and numerical analyses. The plate joint profiles are modeled under various loading and boundary conditions and the finite element method is used for the calculation of stress components and deflections. The TP profile has a high potential to be used in the shipbuilding industry.
\end{abstract}

Keywords

Ship construction, TP profile, HP profile, Finite element analysis, Ship strength

\section{Introduction}

Maritime transportation has a significant role in world trade and the capacity of seaborne trade keeps growing. It is reported [1] that the world's seaborne trade in 2014 was about 50 times larger in terms of tonnage compared to its value in 1975. Moreover, there are about 53,000 [2] merchant ships trading internationally as of 2019. Proportional to the maritime transportation growth, the ship sizes and the number of ship types are also increasing due to economic reasons. In the last decade, the average container ship and bulk carrier capacities have shown an increase of almost 100\% [3]. Despite some depressed periods, a total of about 90 million CGT was constructed and delivered in 2018 [4]. Based on the market size and growth, the consumption of construction materials is one of the primary concerns for the shipbuilding industry to save building costs and to achieve fuel saving. It was stated [5] that the steel cost used in hull construction is about
$8 \%-15 \%$ of the total cost of a commercial ship. Moreover, the weight of the lightship over the total weight is about $14 \%$ for tankers, $30 \%$ for bulk carriers, $35 \%$ for container ships, and $41 \%$ for ro-ro carriers [6]. Therefore, the design and optimization of a ship hull have become important to minimize material, labor, and operational costs.

Structural design rules for ships are mostly based on empirical and experience-based formulations regulated by classification societies [7]. However, these rules mainly target a safe design rather than an optimum one. Specifically, the constructional profile types and numbers and the plate thickness used in the hull structure directly affect the weight and cost of newly built ships. This makes cost efficiency a key factor in the ship design phase. As a result, the development of novel strengthening construction profiles that will decrease the costs or increase the structural reliability plays an important role in the optimized hull design. At the end of the 1800 s, a comprehensive study was performed in which

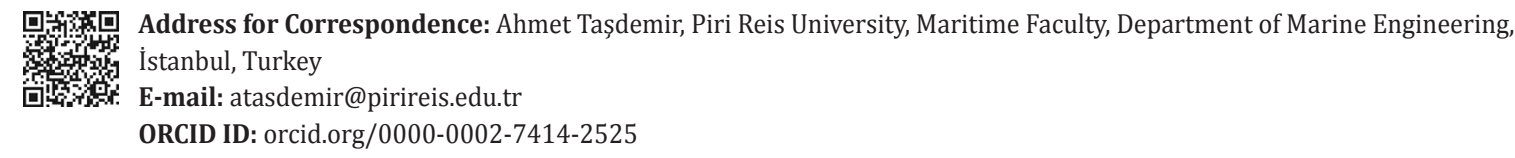
\footnotetext{
ORCID ID: orcid.org/0000-0002-7414-2525

Received: 25.04 .2021 Accepted: 12.08 .2021

To cite this article: A. Taşdemir, S. Nohut and M. Akman, "Analytical and Numerical Analysis of the Strength Performance of a Novel Ship Construction Profile." Journal of ETA Maritime Science, vol. 9(3), pp. 200-209, 2021.

${ }^{(C)}$ Copyright 2021 by the Journal of ETA Maritime Science published by UCTEA Chamber of Marine Engineers 
different profiles (so-called German Profiles) for rolling iron were introduced taking into account the requirements of theory, construction, and rolling technology by the commission of the Association of German Architects and Engineers' Associations and the Association of German Engineers, on whose behalf, Heinzerling and Intze published the German Normal Profile Book [8]. However, these profiles were not fully used in industrial applications. In the following years, construction profiles in different shapes such as bulb flats, tees, channels, and angles have been started to be used in the analysis for shipbuilding.

In recent years, numerical methods have been widely used for the design of ship hulls. The finite element method (FEM) is one of the most preferred tools to solve constructional problems where standardized bulb flats, tees, angles, channels, and rectangular profiles are widely used to stiffen the plates and panels. Nohut and Tasdemir [9] applied a FEM in POSEIDON to accelerate the modeling ship's hull and to analyze the structural hulls, where T-shaped and bulb flats are used in the sections of a car carrier and a multi-purpose vessel. Patel et al. [10] discussed a method based on FEM to assess the strength in service of the loss of surface material due to the corrosion and erosion of marine structures. They reported that the developed code enables handling irregular shapes and differential corrosion thicknesses. Paik et al. [11] developed a novel formulation to analyze the ultimate strength performance of the ship hull including bulb flat stiffened panels. Moreover, they compared the results of the analysis with those of the FEM. Abubakar and Dow [12] analyzed the bulb flats stiffened double bottoms experimentally and numerically to investigate the grounding damage. They proved that the FEM-based results are agreeable with experimental results. Prabowo et al. [13] simulated the grounding behavior of a double bottom stiffened with bulb flats using FEM. Ahmadi et al. [14] used FEM and artificial neural network to analyze and predict the ultimate strength of cracked pitted plates under different geometrical and crack size dimensions. Storheim and Amdahl [15] simulated the effect of the slope of the stress-strain curve (i.e., strain rate), strain localization, and crack propagation during ship collisions using non-linear finite element analysis. Paik et al. [16] carried out benchmark studies for the ultimate limit state assessment of unstiffened plates, stiffened panels, and hull girders stiffened with three different T-shaped profiles using FEM. Xia et al. [17] conducted a numerical study on the strength behaviors of ship hull plates under cyclic loads using FEM. Tasdemir and Nohut [18] investigated the fatigue behaviors of a vertical side web constructed with T-shaped and bulb flat profiles, connected to the main deck of a vessel using three types of finite element analyses. As a result of the study, they recommended weld toe grinding, TIG dressing, or hammer peening to increase the fatigue life of the analyzed part. Gledic et al. [19] used FEM to calculate the strength parameters of the midship including bulb flat stiffened plates under 50 random damage scenarios, where low-cycle fatigue damage is predicted. Shen et al. [20] analyzed the spring-back and cold forming process of hull plates using implicit and dynamic explicit FEM. Rao and Wan [21] studied the wave-plate interaction resulting from the slamming force using the moving particle semi-implicit FEM. Niklas and Kozak [22] analyzed the stress and strain behaviors of toe and root notches on panels using 2D and 3D elements. To sum up, studies related to the ship construction in the literature are based on strength analyses, fatigue estimations, and material and method research along with numerical and experimental investigations of hull sections including standard constructional profiles.

In this study, apart from studies in the literature, the strength performance of a novel construction profile, the so-called TP profile, is investigated and the performance parameters are compared with those of the commonly used conventional bulb flat (HP) and T-shaped profiles. Two cases are set up for the strength performance investigation of the profile joints with plates. In the first case, a beam is fixed from one of its ends and a uniformly distributed load acts normal to the plate. In the second case, the beam is fixed from both ends under a uniformly distributed load, which has the same magnitude and direction as those of Case 1. Euler-Bernoulli beam equations and Timoshenko theorybased beam elements are used for evaluating the bending, shear, and Von-mises stresses along with deflections under cases including different loading and boundary conditions. Moreover, solid elements are used for advanced numerical investigations at the same conditions to analyze the behaviors of the beams under three-dimensional forces.

\section{Methodology}

Bulb flats and T sections, the most commonly used profiles in ship hulls, are suitable for areas where bending moments are dominant [23]. Cross-sectional dimensions of these profiles are generally $160 \mathrm{~mm}$ to $430 \mathrm{~mm}$ in width, and the thickness of the profiles varies between $7 \mathrm{~mm}$ and $20 \mathrm{~mm}$. Within the scope of this article, a novel profile, of which form mimics the bone geometry of living things, is introduced. Figure 1 shows a typical human femur bone [24] and the bone geometry-inspired, dimensionally parametric TP profile.

The top end of the bone consists of nearly symmetrical and curvilinear bulbs next to the centered small channel, which increase the moment of inertia of the geometry relative to the lateral axis as shown in Figure 1. The main 


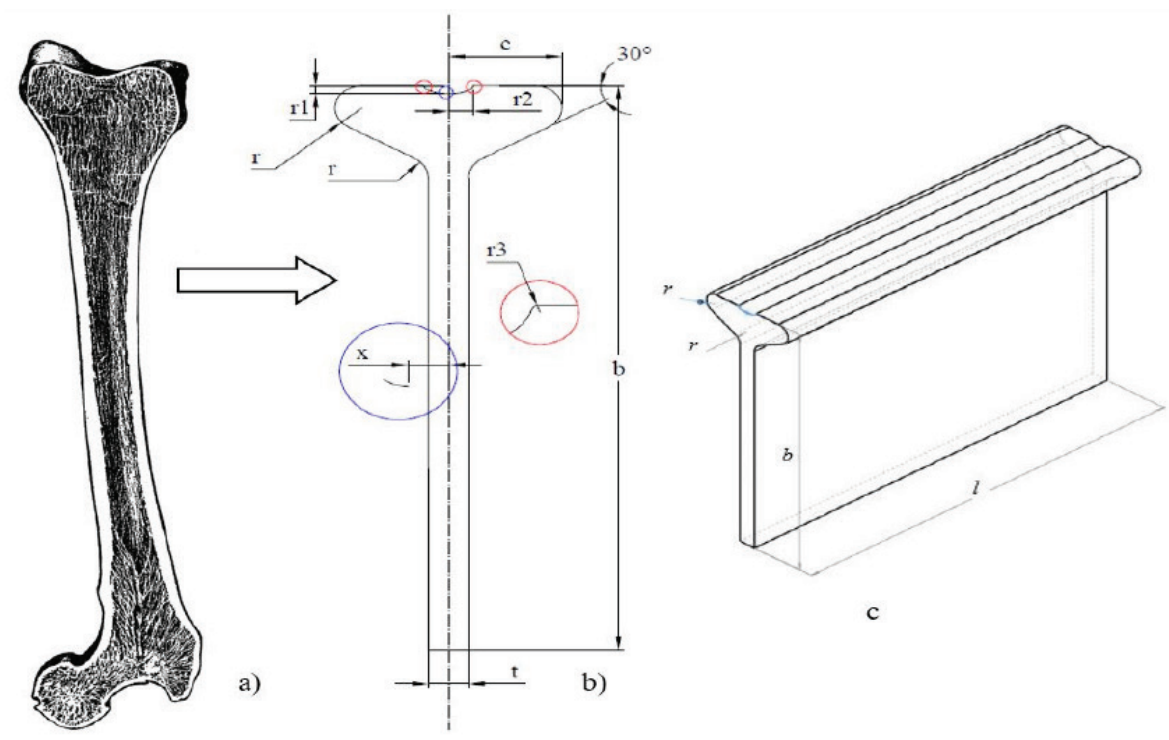

Figure 1. Geometry of (a) a femur (Blaisedell, 1898), (b) TP - front, TP - isometric view

aim for increasing the moment of inertia is to decrease the stresses and deformations on the profile. This principle is used for the form determination of the novel TP profile. In literature, there are many studies on the bone strength analysis supporting the subject including the ultimate strength, buckling, and fatigue investigations particularly in the human femur and tibia bones [25-29].

Dimensions of the TP profile section are scalable by the needs and limits of the thickness ( $\mathrm{t}$ ), height (b), bulb width (c), and radius $\left(r, r_{1}, r_{2}\right)$, which are $t=[3,20] \mathrm{mm}, \mathrm{b}=[80,450]$ $\mathrm{mm}, \mathrm{c}=[18,85] \mathrm{mm}, \mathrm{r}=[4,20] \mathrm{mm}, \mathrm{r}_{1}=[1,10], \mathrm{r}_{2}=[1,20]$, and $r_{3}=[1,5]$. The similarity of TP with the bone is restricted by the shape at the top end, which is the key factor to increase the moment of inertia due to its distance from the neutral axis. As used in the ship construction process, the flat plates are joint to the HP, T, and TP profiles and modeled for the loading cases. Figure 2 shows the cross sections of HP, T, and TP-joint plates.

Cross-sectional areas and weights are selected to be the same for all profiles and plates. The profile-joint plates are modeled as beams in the YZ plane. Structural steel is used and the geometrical and material properties of the profilejoint plates are shown in Table 1.

In addition to common dimensional parameters given in Table 1, other dimensions of the TP profile are $\mathrm{r}=5.5 \mathrm{~mm}, \mathrm{r}_{1}=2 \mathrm{~mm}$, $r_{2}=5 \mathrm{~mm}$, and $c=23 \mathrm{~mm}$. The strength performances of the three profile-joint plates are investigated under two common cases. In Case 1, one end has a fixed support, while the other end is free. In addition, a $40-\mathrm{kN} / \mathrm{m}$ distributed load is applied along the z-axis. In Case 2, both ends have fixed supports and a
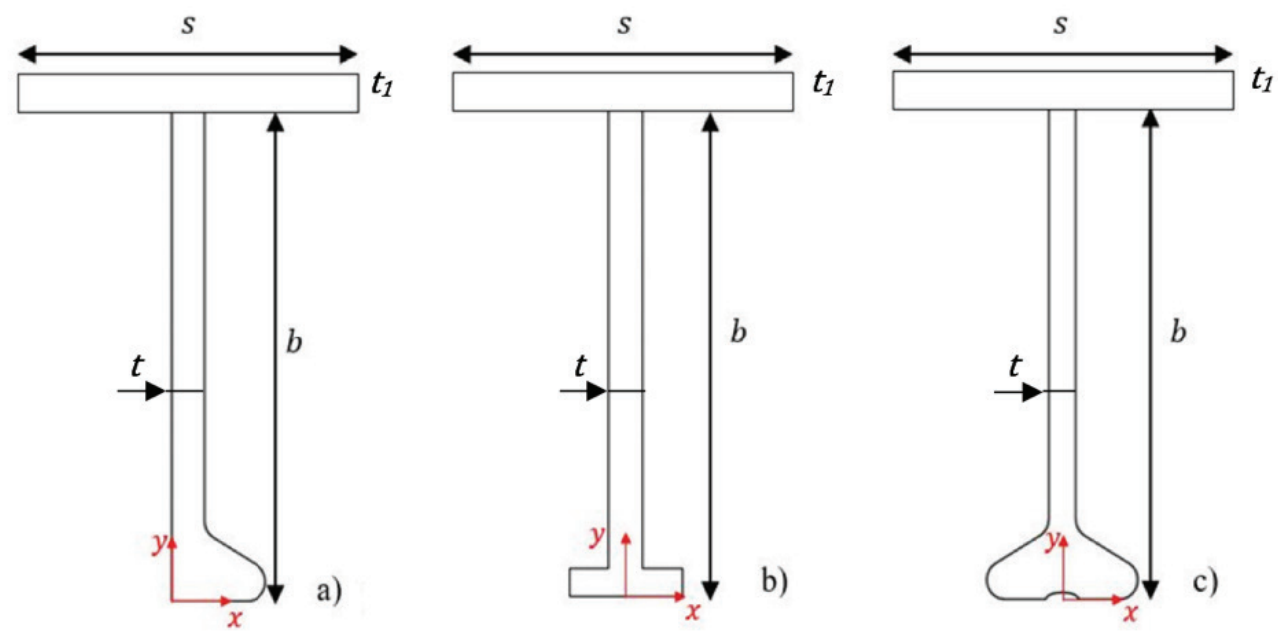

Figure 2. Cross sections of the (a) HP-joint plate, (b) T-joint plate, and (c) TP-joint plate 
Table 1. Geometrical (G) and material (M) properties of the HP, T, and TP-joint plates

\begin{tabular}{|c|c|c|c|c|}
\hline \multicolumn{2}{|r|}{ Properties } & HP Plate & T Plate & TP Plate \\
\hline \multirow{8}{*}{ G } & Height - $b[\mathrm{~mm}]$ & 140 & 140 & 140 \\
\hline & Width $-s[\mathrm{~mm}]$ & 250 & 250 & 250 \\
\hline & Thickness of profile - $t[\mathrm{~mm}]$ & 10 & 10 & 8.24 \\
\hline & Length $-l[\mathrm{~mm}]$ & 500 & 500 & 500 \\
\hline & Distance of the neutral axis from $x$-axis [mm] & 111.11 & 111.91 & 107.43 \\
\hline & Distance of the neutral axis from $y$-axis [mm] & 5.82 & 0 & 0 \\
\hline & Moment of inertia $-I_{x}\left[\mathrm{~mm}^{4}\right]$ & $1.036 \mathrm{e} 7$ & $1.002 \mathrm{e} 7$ & $1.211 \mathrm{e} 7$ \\
\hline & Moment of inertia $-I_{\mathrm{y}}\left[\mathrm{mm}^{4}\right]$ & $1.308 \mathrm{e} 7$ & $1.306 \mathrm{e} 7$ & $1.311 \mathrm{e} 7$ \\
\hline \multirow[t]{3}{*}{ M } & Tensile-compressive yield strength [MPa] & 235 & 235 & 235 \\
\hline & Young's modulus - $E[\mathrm{GPa}]$ & 200 & 200 & 200 \\
\hline & Shear modulus - $G$ [GPa] & 79.3 & 79.3 & 79.3 \\
\hline
\end{tabular}

$40-\mathrm{kN} / \mathrm{m}$ distributed load is applied along the $\mathrm{z}$-axis. Moreover, the profile-connected plates are modeled as rigid bodies.

\section{Finite Element Model}

The Euler-Bernoulli beam theory is widely used for long and slender body strength analysis, assuming that the cross-section of the beam is rigid, remains plane after deformation, and remains normal to the deformed axis [30]. On the other hand, the Timoshenko beam theory, where transverse shear stresses are taken into account, is a first-order shear deformation theory, including that the cross-section of the beam remains plane and undistorted after deformation [31]. The numerical procedure first starts using the BEAM188 element, which is based on the Timoshenko beam theory to compare the results of stresses and deflections with those of the analytical solutions. Cross sections are modeled in the ANSYS 14.5 Static Structural module according to the data given in Figure 2 and Table 1. Line bodies are created and the beam is divided into 100 pieces of BEAM188 elements. BEAM188 is a two-node element in space, providing relationships between transverse shear stresses and strains in the elastic region and can be used for slender beams [32,33]. The element uses linear shape functions resulting in all element solutions along the length being constant. On the other hand, plate-profile connections and weld effects are ignored in 3D models. The profile and the plates are designed separately and formed in one part in the design modeler module of ANSYS. Therefore, the profileconnected plates behave like a one-piece solid body in FEM models. SOLID186 and SURF154-type elements are used during the 3D meshing process. The SOLID186 element is a high-order three-dimensional 20-node network element that has three degrees of freedom per node and the element is used in cases of plasticity, hyperelasticity, creep, high stresses, and high deflection [33]. Apart from BEAM188, SOLID186 is used for high-order theories including various load distributions in 3D applications. Moreover, SURF154 is used for solving problems under different load and surface effects in 3D structural analyses. SURF154 is overspread onto the face of 3D elements that are determined by four to eight nodes and the material's properties. Besides, the plane force over the unit length is used for calculating the stress stiffness matrix and load vectors [33]. Figure 3 shows the meshed plates.

The number of elements used is 49410, 42960, and 62062 for the HP plate, T plate, and TP plate, respectively. The aspect ratio of the elements is selected to be less than 5 for stress and less than 10 for the deformation analyses to increase the accuracy of the results [34]. Therefore, the maximum aspect ratios of $\mathrm{HP}, \mathrm{T}$, and TP plates are 2.06, 1.76, and 4.96, respectively. On the other hand, the minimum orthogonal quality of $\mathrm{HP}, \mathrm{T}$, and TP plates are $0.71,0.81$, and 0.74 , respectively.

\section{Results and Discussion}

The bending, shear, and equivalent Von-Mises stresses along with the deflections are calculated under two cases. Analytical calculations are verified using beam elements. 
After, the two cases are modeled by 3D elements to include the shear forces.

\subsection{Numerical Simulations with Beam Elements}

Numerical solutions show that the maximum bending stress is obtained at a fixed support as indicated in Table 2. Since the center of mass of the investigated profiles is at different locations, the vertical distances of the neutral axis from the origin in the cross sections and the moments of inertia are different. As a result, different bending stresses are obtained. The maximum bending stresses are calculated as 53.6 MPa, 55.8 MPa, and 44.4 MPa for HP, T, and TP profiles, respectively. Although the maximum stress in $\mathrm{HP}$ and $\mathrm{T}$ profiles are very close to each other, the maximum bending stress of the TP is quite different. Here, the maximum bending stresses are obtained at the bottom side of the sections. The values for the top side of the cross sections are 18.8 MPa, 19 MPa, and 17.6 MPa for HP, T, and TP profiles, respectively. Similar to the bending stress distribution, the maximum deflection is obtained in the section of the $T$ profile as $0.155 \mathrm{~mm}$. The deflection of the TP profile is about $0.13 \mathrm{~mm}$, which is about $13 \%$ less than that of the HP and T sections. Table 2 shows the numerical and analytical results. It is seen that the analytical and numerical stress and deflection results are very close to each other. This is based on the beam approach and slender models that decrease the deviations.

\subsection{Numerical Simulations with 3D Elements}

The cross sections are extruded in the z-axis to analyze the strength performances of 3D bodies. Solid elements are used for advanced numerical analysis. The loading and boundary conditions of the models are the same as those of the previous section. Figure 4 shows the representation of the loading and boundary conditions on the 3D model. Due to the occurrence of some singularities at points of constraints, two-section planes (XY plane) are introduced at $5 \%$ and $50 \%$ of the total length of the models to evaluate the maximum values. The presented stress distributions are taken at 0.05l (Plane $\mathrm{C}$ in Figure 4) and the deflections are based on the XY plane at 0.5l (Plane B in Figure 4) or free ends.

\subsubsection{Case 1}

In Case 1, the structure is fixed at one end and a $40-\mathrm{kN} / \mathrm{m}$ uniformly distributed load is applied on the top surface of the plate. The maximum bending stress occurred at the fixed point of the structure. The maximum bending stresses (normal stress in the z-axis) are obtained at the bottom of

Table 2. Numerical and analytical results for the sections ( $N$ for numerical, A for analytical)

\begin{tabular}{|c|c|c|c|c|c|c|c|}
\hline \multirow{3}{*}{ Solution } & Parameter & \multicolumn{3}{|c|}{ Case 1 } & \multicolumn{3}{|c|}{ Case 2 } \\
\cline { 2 - 8 } & & HP & T & TP & HP & T & TP \\
\hline \multirow{3}{*}{ N } & Max. moment [kNm] & 5 & 5 & 5 & 0.833 & 0.833 & 0.833 \\
\cline { 2 - 8 } & Max. bending stress [MPa] & 53.612 & 55.803 & 44.381 & 8.936 & 9.308 & 7.399 \\
\cline { 2 - 8 } & Max. deflection in y-axis [mm] & 0.1544 & 0.1553 & 0.1296 & 0.0032 & 0.0033 & 0.0027 \\
\hline \multirow{3}{*}{ A } & Max. moment [kNm] & 5 & 5 & 5 & 0.833 & 0.833 & 0.833 \\
\cline { 2 - 8 } & Max. bending stress [MPa] & 53.618 & 55.806 & 44.351 & 8.936 & 9.301 & 7.391 \\
\cline { 2 - 8 } & Max. deflection in y-axis [mm] & 0.1508 & 0.1550 & 0.1290 & 0.0031 & 0.0032 & 0.0026 \\
\hline
\end{tabular}
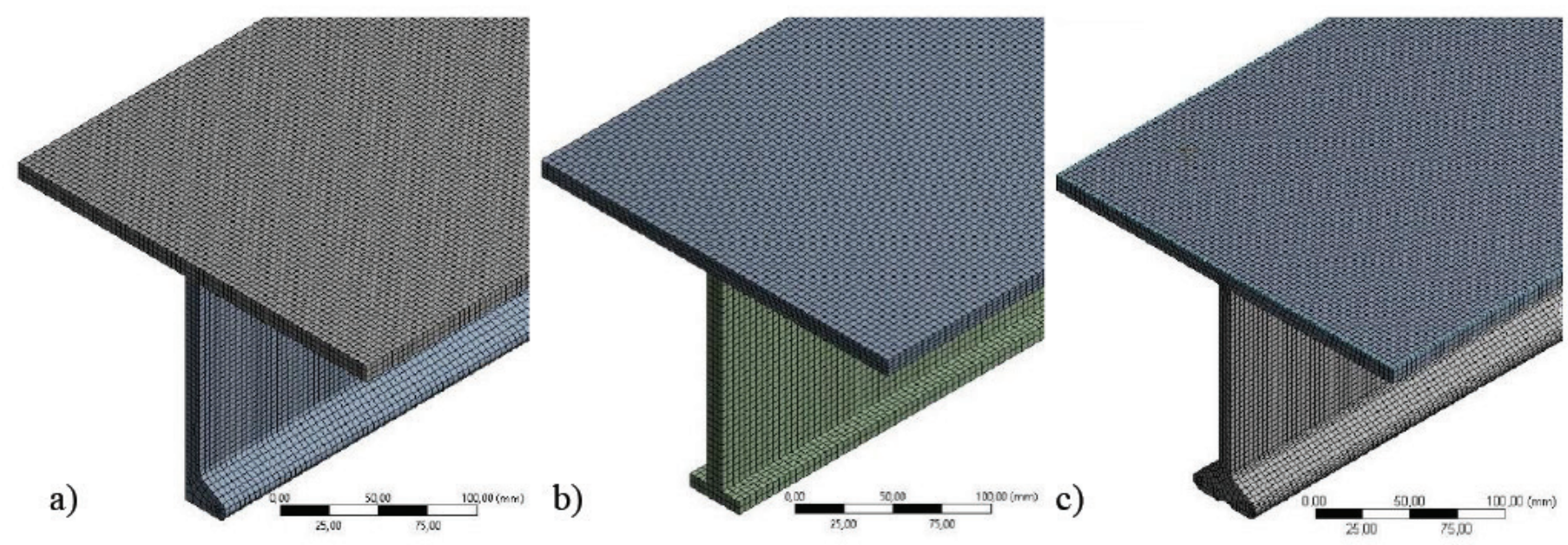

Figure 3. Meshed (a) HP, (b) T, and (c) TP-joint plates 

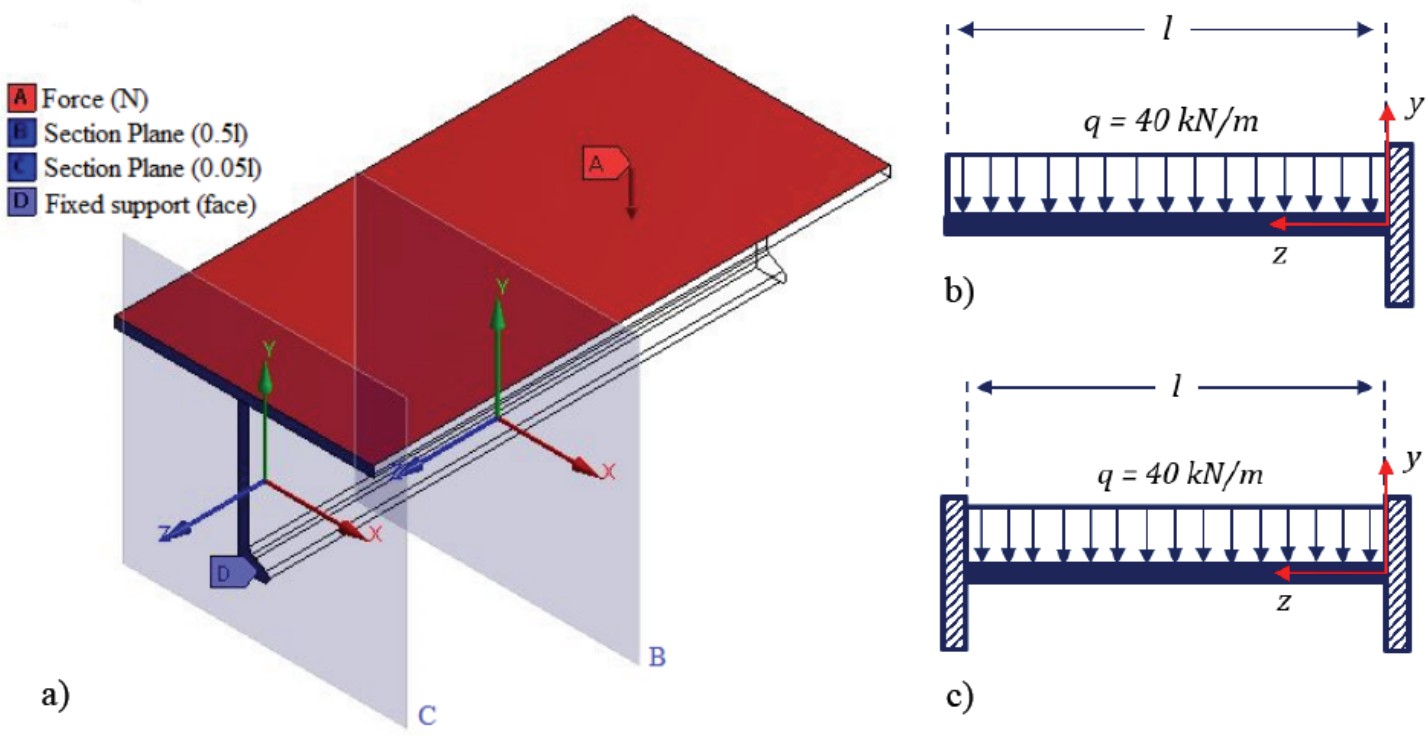

b)

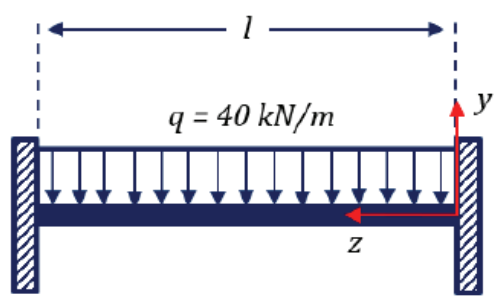

c)

Figure 4. (a) 3D model and the representation of the loading and boundary conditions for (b) Case 1 and (c) Case 2

the profiles. The maximum stresses are recorded as 64.8 $\mathrm{MPa}$, 51.9 MPa, and 44.9 MPa for HP, T, and TP profiles, respectively. This shows that the maximum bending stress that occurs in the TP profile is lower than those of the other two profiles. Furthermore, it should be stated that the HP is an asymmetrical profile and its centroid is $5.82 \mathrm{~mm}$ away from the y-axis. Therefore, the profile is exposed to the torsion around the z-axis. Besides, the shear stresses are very small in comparison with the bending stresses. The cross sections had nearly uniform shear stress distributions, where the shear stress is concentrated at the corners and fillets of the profiles. Note that the average shear stress in the TP section is higher than that of the HP and T. Figure 5 shows the equivalent Von-Mises stresses at the profile cross sections.

Similar to the bending stress concentration, the maximum Von-Mises stress is $64.8 \mathrm{MPa}$ at the bottom corner region of the HP profile, which is larger than that of the symmetrical $\mathrm{T}$ and TP profiles. Close to the plate region, the Von-Mises stresses are decreasing and the obtained maximum VonMises stress at the TP section is $23.9 \mathrm{MPa}$. Note that the obtained maximum values are less than the yield limit of the

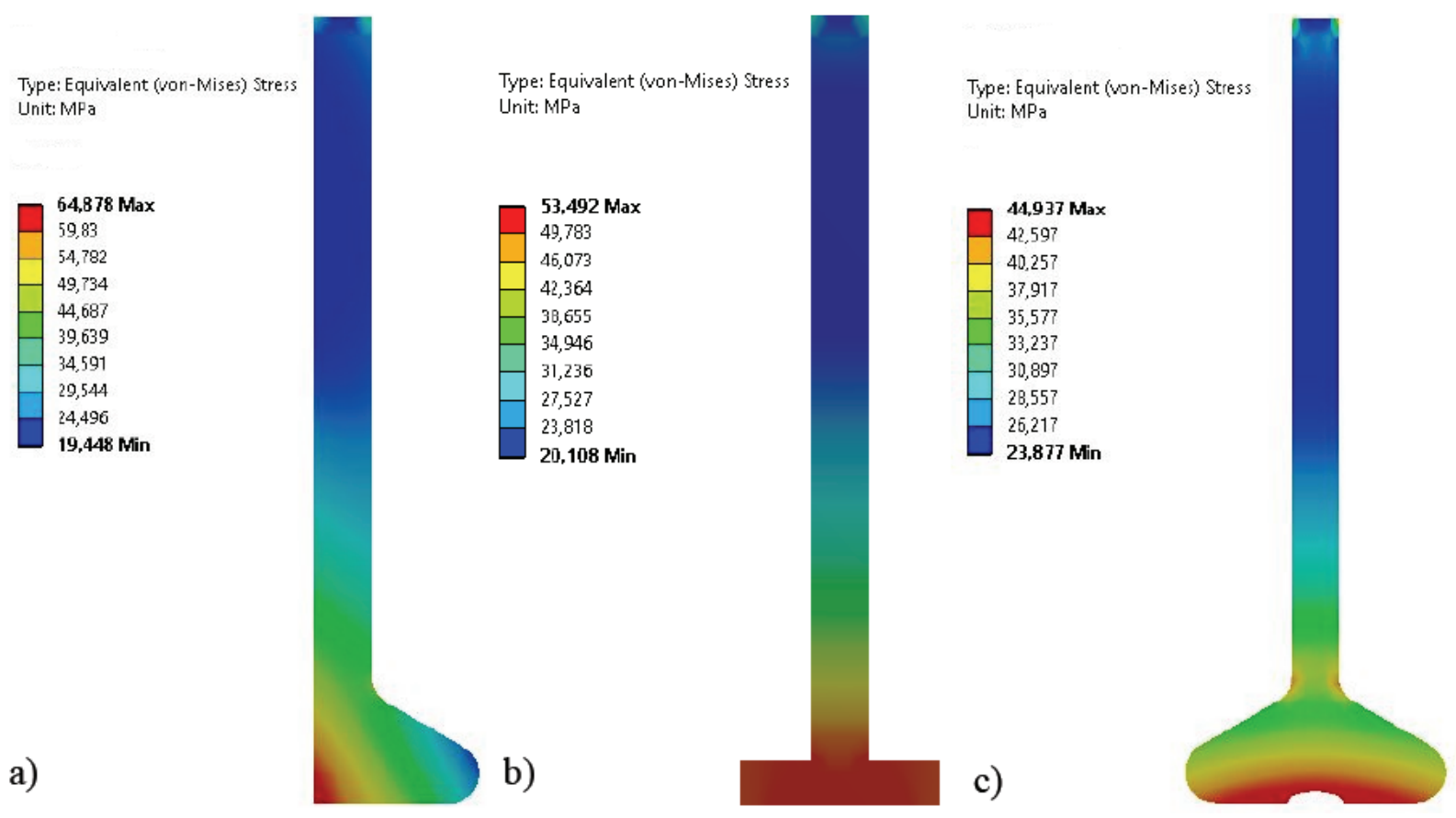

Figure 5. Von-Mises stress distribution at the profile cross sections: (a) HP, (b) T, and (c) TP 
material. Figure 6 shows the distribution of the deflections in the cross sections. According to the contours, the maximum deflections in the y-axis are $0.237 \mathrm{~mm}, 0.202 \mathrm{~mm}$, and 0.185 $\mathrm{mm}$ for the HP, T, and TP profiles, respectively.

The deflection in the y-direction is maximum for the HP profile. Furthermore, the HP section experiences some torsion during bending with a deflection of $0.19 \mathrm{~mm}$ on the $\mathrm{x}$-axis. The $\mathrm{x}$-axis deflections for the $\mathrm{T}$ and $\mathrm{TP}$ profiles are negligible based on the centroid's position.

On the other hand, the maximum Von-Mises stress values on the connecting plates are obtained as $47.32 \mathrm{MPa}, 41.38$ $\mathrm{MPa}$, and 41.27 MPa for the HP-joint, T-joint, and TP-joint plates, respectively. The HP-joint plate has the maximum Von-Mises stress because of asymmetry in the section that causes torsion. T-joint and TP-joint plates are symmetrical and magnitudes of the Von-Mises stress on the plates are close to each other. Besides, the maximum deflections on the connecting plates are obtained as $0.401 \mathrm{~mm}$ for the HP plate, $0.321 \mathrm{~mm}$ for the T plate, $0.323 \mathrm{~mm}$ for the TP plate. Compared to analytical solutions based on the beam theory, results obtained from 3D models are quite different. This is because the beam theory does not include shear strain variations that should be calculated for moderately thick and short beams [35].

\subsubsection{Case 2}

In Case 2, the structure is fixed at both ends and a 40$\mathrm{kN} / \mathrm{m}$ uniformly distributed load is applied on the top surface of the plate. According to the bending stress results, the maximum bending stresses of profiles are less in comparison with those obtained in Case 1. The HP profile is exposed to a $70 \%$ higher bending stress than the $\mathrm{T}$ and TP profiles due to the geometrical properties mentioned in the previous section. Moreover, $\mathrm{T}$ and TP profiles show approximately the same bending resistances so that the maximum bending stress of the TP profile is only $6 \%$ less than that of the T profile. On the other hand, proportional to the decrease of the maximum moment compared to Case 1 , shear stresses are very small. The HP profile has better shear resistance in comparison with other sections. The average shear stress in the TP section is higher than those of the HP and T. In addition, the symmetrical profiles have symmetrical shear stress distributions. Figure 7 shows the Von-Mises stresses for the profile cross sections in Case 2. The average Von-Mises stresses are about $8.5 \mathrm{MPa}$ for all sections. Note that the exerted force is relatively small for two-side fixed bodies.

Figure 8 shows the deflections in the cross sections. According to the results, average deflections in the y-axis are $0.0155 \mathrm{~mm}, 0.0141 \mathrm{~mm}$, and $0.0154 \mathrm{~mm}$ for the HP, $\mathrm{T}$, and TP profiles, respectively. As a result, no significant difference is observed in the deflection of structures in the $\mathrm{y}$-direction under stated boundary and loading conditions.

Besides, the maximum Von-Mises stresses on the connecting plates are 29.17 $\mathrm{MPa}$, 28.44 $\mathrm{MPa}$, and 28.64 $\mathrm{MPa}$ for the HP-joint, T-joint, and TP-joint plates, respectively. The maximum Von-Mises stress is obtained from the HP-joint plate, while the T-joint and TP-joint plates are quite similar. The maximum deflections on the connecting plates are obtained as $0.234 \mathrm{~mm}$ for the HP plate, $0.224 \mathrm{~mm}$ for the

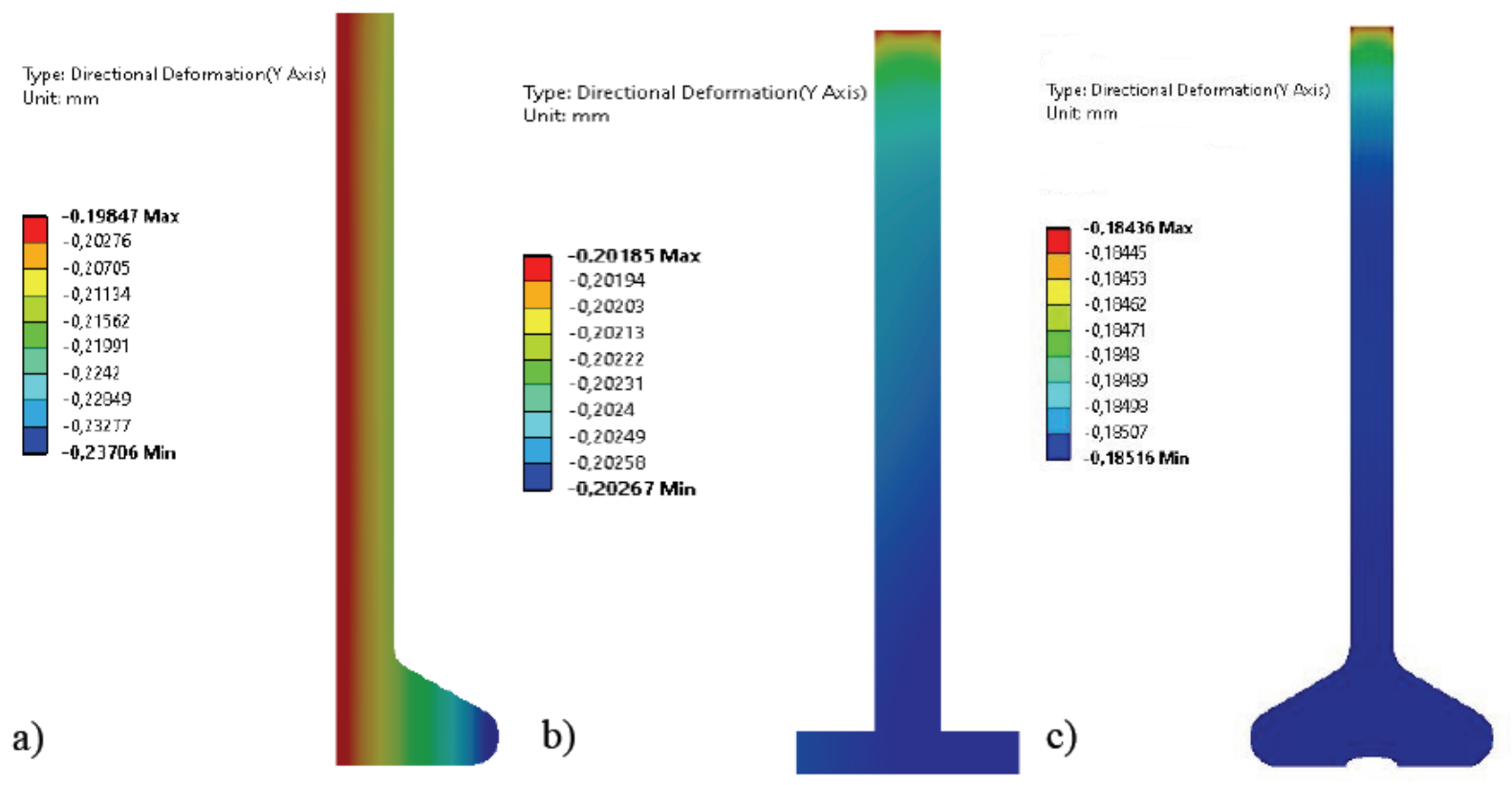

Figure 6. Distribution of deflections in the y-axis for the cross sections: (a) HP, (b) T, and (c) TP 


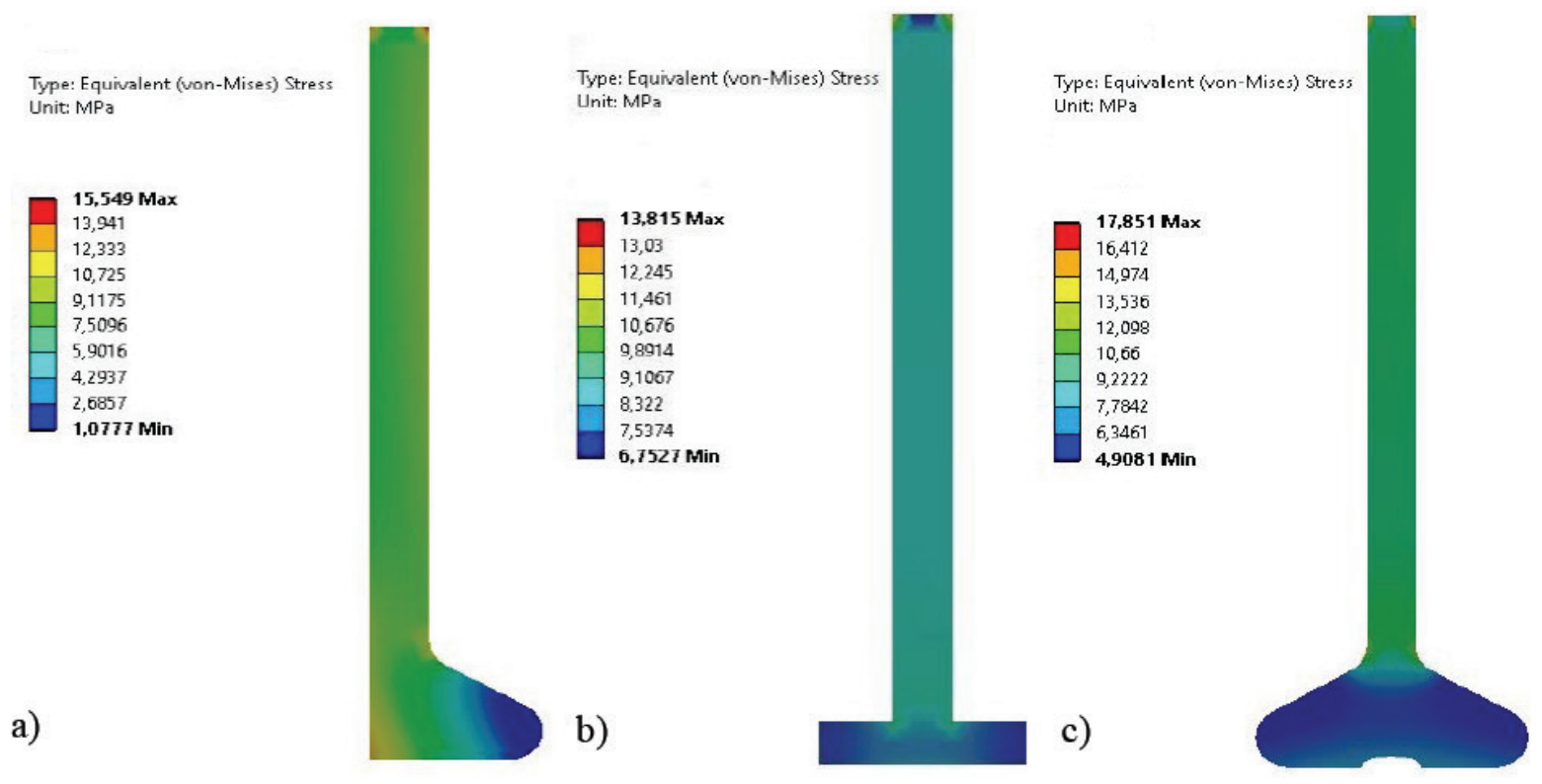

Figure 7. Von-Mises stress distribution of the profile cross sections: (a) HP, (b) T, and (c) TP

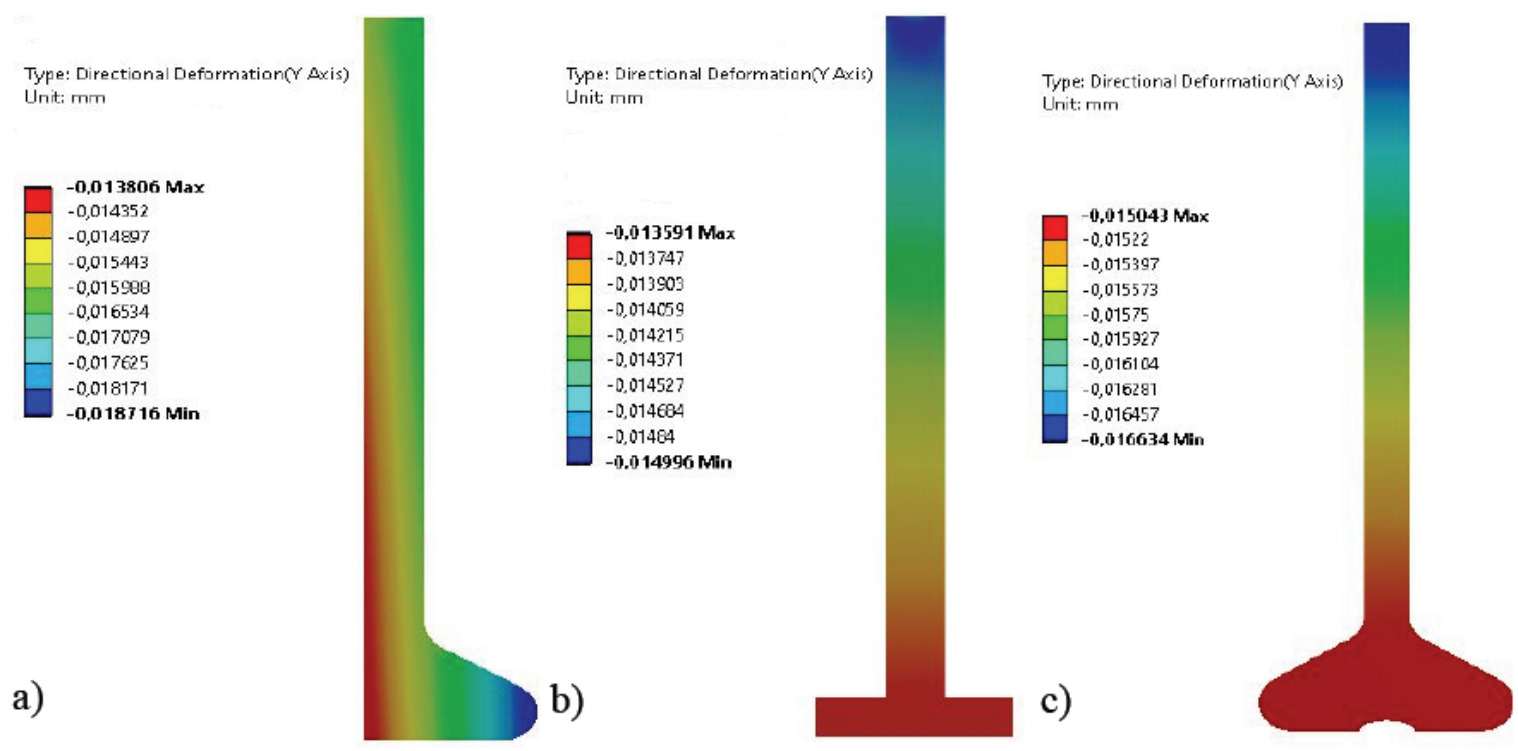

Figure 8. Deflections in the y-axis for the profile cross sections: (a) HP, (b) T, and (c) TP

T plate, and $0.229 \mathrm{~mm}$ for the TP plate. The HP-joint plate seems less favorable in comparison with other sections because of the reasons explained in Case 1.

\section{Conclusion}

Strength performances of the HP, T, and TP profile-joint plates are investigated under two common loading cases used in shipbuilding. The bending, shear, and equivalent stress along with the deflections of the profile-joint plates are analyzed numerically and analytically. Results indicate that the equivalent stress of the TP profile is about $30 \%$ and $16 \%$ less compared to those of HP and $\mathrm{T}$ profiles, respectively. Moreover, the deflection of the TP profile is calculated as 21\% and 8\% less compared with those of HP and T profiles, respectively. As a result, the following conclusions are drawn:

- Symmetrical profiles eliminate the additional torsion under bending cases. Therefore, stresses and deflections are remarkably lower compared to the results of the HP profile.

- The TP profile shows a higher equivalent stress resistance and has less deflection in cases compared to the HP and T profiles. 
- There are very small differences between the beam element used for the numerical and analytical solutions. However, 3D effects including axial shear stresses and deformations highly influence the results.

- Results show that the TP profile can increase the hull performance and contribute to fuel-saving depending on the lighter hull.

- The study gives promising results that the TP profile has an important potential to decrease the building and labor costs based on less material consumption during ship construction.

In future work, the optimization of the TP profile will be performed for different scales under more complex loading cases to increase the axial moments of inertia. Furthermore, the optimal design will be verified using both experiments and numerical computations.

\section{Authorship Contributions}

Concept design: A. Taşdemir, S. Nohut, Data Collection or Processing: S. Nohut, M. Akman, Analysis or Interpretation: A. Taşdemir, S. Nohut, M. Akman, Literature Review: A. Taşdemir, M. Akman, Writing, Reviewing and Editing: A. Taşdemir, S. Nohut, M. Akman.

Funding: The author(s) received no financial support for the research, authorship, and/or publication of this article.

\section{References}

[1] UNCTAD, "Developments in international seaborne trade," Review of Maritime Transport 2014, pp. 1-25. https://doi. org/10.18356/e9e3b605-en

[2] Statista, "The world merchant fleet," 2019. [online]. Available: https: //www.statista.com/statistics/264024/number-ofmerchant-ships-worldwide-by-type/. [Retrieved: 8 October 2020].

[3] S. Parks, "The Impact of Mega Ships - Case-Specific Policy Analysis. International Transport Forum," 2015, pp. 5.

[4] OECD, "Shipbuilding Market Developments", 2018. [Online]. Available: https://https://www.oecd.org/sti/ind/shipbuildingmarket-developments-Q2-2018.pdf. [Accessed: Oct. 8, 2020].

[5] D. Broderick, R. Kattan and P. Wright, "The design challenges associated with coating ships," 11th International Symposium on Practical Design of Ships and Other Floating Structures, PRADS, Houston, Texas, 2010, pp. 635-643.

[6] S.M. Hamberger, B.D. Blackwell, L.E. Sharp, and D. B. Shenton, "H-1 design and construction," Fusion Technology, vol. 17, pp. 123-130, Jan 1990.

[7] Y.V. Satish Kumar and M. Mukhopadhyay, "Finite element analysis of ship structures using a new stiffened plate element," Applied Ocean Research, vol. 22, pp. 361-374, Dec 2000.

[8] 0. Lueger, "Lexikon der gesamten technik und ihrer hilfswissenschaften," Stuttgart: Leipzig, 1908, pp. 663-673.

[9] A. Tasdemir, and S. Nohut, "Practical experience with efficient generation of finite-element models of ships using POSEIDON," 11th International Conference on Computer and IT Applications in the Maritime Industries, Liege, Belgium, 2012, pp. 19-26.

[10] A.K.P. Patel, S.K. Satsangi and R. Verma, "Analysis of ship structural plate panels during service by the method of finite elements," Journal of The Institution of Engineers (India): Series C, vol. 100, pp. 433-437, 2019.

[11] J.K. Paik, D.K. Kim, D.H. Park, H.B. Kim, A.E. Mansour, J.B. Caldwell, "Modified Paik-Mansour formula for ultimate strength calculations of ship hulls," Ships and Offshore Structures, vol. 8, pp. 245-260, 2013.

[12] A. Abubakar and R.S. Dow, "Simulation of ship grounding damage using the finite element method," International Journal of Solids and Structures, vol. 50, pp. 623-636, Mar 2013.

[13] A.R. Prabowo, T. Putranto and J.M. Sohn, "Simulation of the behaviour of a ship hull undergrounding: Effect of applied element size on structural crashworthiness," Journal of Marine Science and Engineering, vol. 7, pp. 1-15, Aug 2019.

[14] F. Ahmadi, A. Rahbar Ranji and H. Nowruzi, "Ultimate strength prediction of corroded plates with center-longitudinal crack using FEM and ANN," Ocean Engineering, vol. 206, pp. 107- 281, Jun 2020.

15] M. Storheim and J. Amdahl, "On the sensitivity to work hardening and strain-rate effects in nonlinear FEM analysis of ship collisions," Ships and Offshore Structures, vol. 12, pp. 100-115, 2017.

[16] Paik, Jeom Kee, Kim, B. J., and Seo, J. K., "Methods for ultimate limit state assessment of ships and ship-shaped offshore structures: Part I-Unstiffened plates," Ocean Engineering, vol. 35, pp. 261-270, Aug 2007.

[17] T. Xia, P. Yang, C. Li and K. Hu, "Numerical research on residual ultimate strength of ship hull plates under uniaxial cyclic loads," Ocean Engineering, vol. 172, pp. 385-395, Jan 2019.

[18] A. Tasdemir and S. Nohut, "Fatigue analysis of ship structures with hinged deck design by finite element method. A case study: Fatigue analysis of the primary supporting members of 4900 PCTC," Marine Structures, vol. 25, pp. 1-12, Oct 2011.

[19] I. Gledic, J. Parunov, P. Prebeg and M. Corak, "Low-cycle fatigue of ship hull damaged in collision," Engineering Failure Analysis, vol. 96, pp. 436-454. Nov 2018.

[20] W. Shen, R. Yan, S. Li, and L. Xu, "Spring-back analysis in the cold-forming process of ship hull plates," International Journal of Advanced Manufacturing Technology, vol. 96, pp. 2341-2354, May 2018.

[21] C. Rao and D. Wan, "Numerical study of the wave-induced slamming force on the elastic plate based on MPS-FEM coupled method," Journal of Hydrodynamics, vol. 30, pp. 70-78, Oct 2017.

[22] K. Niklas, and J. Kozak, "The effect of numerical $2 \mathrm{~d}$ and $3 \mathrm{~d}$ fem element modelling on strain and stress distributions at laser weld notches in steel sandwich type panels," Polish Maritime Research, vol. 25, pp. 121-127, 2018.

[23] W. Fricke, "Ship Structural Design I," Hamburg: Hamburg University of Technology, 2009.

[24] A.F. Blaisedell, "Our bodies and how we live", Boston:Ginn \& Company, 1898.

[25] E. Arendt, J. Agel, C. Heikes and H. Griffiths, "Stress injuries to bone in college athletes: a retrospective review of experience at a single institution," The American Journal of Sports Medical, vol. 31, pp. 959-968, Nov 2003. 
[26] E.M. Hennig, T.L. Milani and M.A. Lafortune, "Three-dimensional acceleration of the tibia during walking and running," Journal of Applied Biomechanics, vol. 9, pp. 306-314.1993.

[27] M.A. Lafortune, "Three-dimensional acceleration of the tibia during walking and running," Journal of Biomechanics, vol. 24, pp. 877-886, May 1991.

[28] C. Milgrom, A. et al. "In-vivo strain measurements to evaluate the strengthening potential of exercises on the tibial bone," The Bone \& Joint Journal, vol. 82, pp. 591-594, May 2000.

[29] A.S. Tenforde, E. Kraus and M. Fredericson, "Bone stress injuries in runners," Physical Medicine \& Rehabilitation Clinics, vol. 27, pp. 139-149, Feb 2016.

[30] O.A. Bauchau and J.I. Craig, "Euler-Bernoulli beam theory," in Solid Mechanics and Its Applications, Vol 163, Structural Analysis, O.A. Bauchau and J.I. Craig, Eds. Dordrecht: Springer, 2009.

[31] J.N. Reddy, Energy Principles and Variational Methods in Applied Mechanics. 3rd ed. Hoboken, New Jersey: John Wiley \& Sons Inc., 2017.
[32] H. Zohoor, and F. Kakavand, "Timoshenko versus Euler-Bernoulli beam theories for high speed two-link manipulator," Scientia Iranica, vol. 20, pp. 172-178, Feb 2013.

[33] ANSYS Inc. 2017. SOLID186 Element Description [Online], Available: https://www.mm.bme.hu/ gyebro/files/ans_help_ v182/ans_elem/Hlp_E_SOLID186.html. [Accessed: Oct. 7, 2020]

[34] G. Bekdaş and N.K. Öztorun, "Aspect ratio factor for finite element method analysis of axially symmetric cylindrical shell walls," Engineering Structures and Technologies, vol. 6, pp. 169177, Mar 2015.

[35] M.E Onyia and E.O. Rowland-Lato, "Finite element analysis of timoshenko beam using energy separation principle," International Journal of Engineering Research and Technology, 2020, vol. 13, pp. 28-35. 